\title{
Crack formation within a Hadfield manganese steel crossing nose
}

Dhar, Somrita; Danielsen, Hilmar K.; Fæster, Søren; Rasmussen, Carsten; Zhang, Yubin; Juul Jensen, Dorte

\section{Published in:}

Wear

Link to article, DOI:

10.1016/j.wear.2019.203049

Publication date:

2019

Document Version

Peer reviewed version

Link back to DTU Orbit

Citation (APA):

Dhar, S., Danielsen, H. K., Fæster, S., Rasmussen, C., Zhang, Y., \& Juul Jensen, D. (2019). Crack formation within a Hadfield manganese steel crossing nose. Wear, 438, [203049].

https://doi.org/10.1016/j.wear.2019.203049

\section{General rights}

Copyright and moral rights for the publications made accessible in the public portal are retained by the authors and/or other copyright owners and it is a condition of accessing publications that users recognise and abide by the legal requirements associated with these rights.

- Users may download and print one copy of any publication from the public portal for the purpose of private study or research.

- You may not further distribute the material or use it for any profit-making activity or commercial gain

- You may freely distribute the URL identifying the publication in the public portal

If you believe that this document breaches copyright please contact us providing details, and we will remove access to the work immediately and investigate your claim 


\title{
Crack formation within a Hadfield manganese steel crossing nose
}

\author{
Somrita Dhar ${ }^{1}$, Hilmar K Danielsen ${ }^{1}$, Søren Fæster ${ }^{1}$, Carsten Rasmussen², Yubin Zhang ${ }^{3}$ and Dorte Juul Jensen ${ }^{3}$ \\ ${ }^{1}$ Department of Wind Energy, Technical University of Denmark, Ris $\varnothing$ Campus, Roskilde, DK- 4000, Denmark \\ ${ }^{2}$ Banedanmark, Amerika plads 15, Copenhagen, DK-2100, Denmark \\ ${ }^{3}$ Department of Mechanical Engineering, Technical University of Denmark, Kgs. Lyngby, DK-2800, Denmark
}

\begin{abstract}
:
Switches and crossings in rail networks suffer from complex loading which may induce severe damage and defects, including formation of cracks that can result in rail breakage. This paper focuses on the microstructure and crack network in a damaged Hadfield manganese steel crossing nose. The extent of deformation has been quantified by hardness measurements, optical microscopy and scanning electron microscopy (SEM) including electron back scattering diffraction (EBSD). It is found that the wheel contact causes high deformation hardness of over $600 \mathrm{HV}$, around three times that of the base material, and the strain hardening extends up to a depth of about $10 \mathrm{~mm}$ from the running surface. Microscopy indicates the deformation microstructure is composed of bands of both deformation twins and deformation induced dislocation boundaries. The complex crack network within the nose of the crossing has been investigated using 3D X-ray tomography, where both surface and subsurface cracks are detected with the majority of the cracks originating from the surface. The crack network has been related to the observed deformation microstructure and it has been found that although the hardening and the deformation of the Hadfield manganese steel is quite different from that of commonly used pearlitic rail steels, the crack morphologies are found to be quite similar for the two materials.
\end{abstract}

Keywords: Rail, rolling contact fatigue (RCF), Hadfield manganese steel, twinning, 3D X-ray tomography, EBSD.

\section{Introduction:}

Switches and crossings (S\&Cs) are an essential part of any railway network, enabling trains to be directed from one track onto another at railway junctions, allowing for the necessary flexibility during train operations. At the same time they are also the most vulnerable part of the railway network, suffering from peak stresses due to their greater geometric complexity compared to normal tracks. When a train passes, from the wing rail to the nose or vice versa depending on the direction of the traffic, either the nose or the wing will suffer from impact stresses due to the discontinuities in the rail as well the normal rolling contact stresses, often causing fatigue cracks and spallation [1]. In this work a Hadfield manganese steel crossing nose is investigated and the crack formation is characterized.

Various numeric studies [2-6] have been conducted in the past to assess the severity of loading and damage on railway crossings. It has been calculated that the stresses and the equivalent plastic strain in the crossing are very sensitive to train speeds as well as track conditions. Large contact and impact forces can lead to plastic deformation as well as severe defects such as squashing and lipping or crack formation and spallation, which may ultimately lead to catastrophic failures.

Hadfield manganese steel has an austenitic fcc structure and is a common material choice for railway crossings due to its excellent work hardening ability, large stress intensity factor, suitable strength, high toughness and good wear resistance. Repeated transient impact and contact stresses will harden the top surface of a Hadfield manganese crossing. However eventually fatigue cracks may develop both at the surface and beneath it. There are only few studies of the relations between the deformation microstructure and the crack propagation within the nose of Hadfield manganese steel crossings published in the open literature [1,7-8]. These studies indicate that the deformation in this steel is not uniform and several deformation mechanisms have been reported. A discontinuous dynamic recrystallized layer was observed on the worn surface of a manganese crossing in one study, whereas the aggregation of vacancy clusters due to deformation leading to cracking has been reported in another study.

Previous works [9-12] on crack formation in rail steels have almost exclusively been done on normal pearlitic steel grades. Here it is found that the microstructure changes during service due to plastic deformation, which is important for crack propagation as it influences the crack path. Cracks tend to follow the direction of least resistance (minimum energy), which depends on the properties and the microstructure in front of the crack tip [13]. With service surface cracks on the rails are unavoidable, and they generally appear at an angle to the surface due to rolling contact fatigue, where they may continue to propagate downwards into the rail causing rail break or reverse the path returning to the surface causing spallation. Brouzoulis et al [14] demonstrated that cracks with shallow angles to the surface are expected to propagate back to the surface while deeper cracks propagate downwards, however inhomogeneity in the microstructure may influence the crack path [9]. 
Mapping of rail cracks has traditionally been done by serial sectioning which is a destructive test with repeated grinding, polishing and imaging of the cross section in order to acquire data of the crack network in three dimensions. Examples include Garnham et al [12] making schematic representations of the crack geometries in pearlitic rails and Schilke et al [9] studying the crack growth on normal pearlitic grade R350HT rail steel. A non-destructive 3D X-ray computerized tomography technique was used by Jessop et al [10] and Zhou et al [11] for visualizing crack networks, where the crack and its side branches could be visualized with high resolution in 3D in pearlitic grade rail steels. Naeimi et al [15] also reconstructed squat defects at different growth stages using this technique. However, all of these studies on 3D crack networks were done on normal grade pearlitic steel used in straight tracks. Crack propagation for crossing noses in Hadfield manganese steel has not been investigated to the best of the authors' knowledge. The load cases in the nose of crossings are quite different from straight tracks, with the material and microstructure behavior also being quite different in case of the Hadfield manganese steel; thus there may be significant differences in the damage mechanisms and nature of crack propagation.

This paper characterizes the deformation and damage induced by rolling contact fatigue and impact on a Hadfield manganese steel crossing nose, which has been in service in the rail network for five years. Currently, only few papers are available on failure analysis of Hadfield manganese steel crossings [1, 7-8, 16] and these focus on local microstructure changes and crack initiation. This paper is focused on the crack propagation and crack morphology of larger crack networks which had developed in the investigated nose, and how they compare to the damage progression in normal pearlitic rail grade steel. The crack network has been analyzed in detail using X-ray tomography measurements, providing 3-D mapping of the crack network within a fairly large volume, and the deformed microstructure and its correlation to the crack network have been studied by optical and scanning microscopy.

\section{Experimental Procedure:}

The Hadfield manganese steel crossing investigated in this study was a 1:14 with radius 500 placed in straight track on wooden sleepers and was extracted from the Danish rail network where it had been in service for five years with an annual traffic density of approximately 14 MGT. Most of the traffic (around 99\%) was in the direction towards the nose from the wing rail; hence the nose was the most severely damaged component. Around $80 \%$ of the traffic is passenger trains, where some pass the crossing at full speed (up to $180 \mathrm{~km} / \mathrm{h}$ ) and some with a low but accelerating speed due to a stop at a nearby station. The remaining traffic is freight trains which pass the crossing with up to $120 \mathrm{~km} / \mathrm{h}$. Recent monitoring (2016-2018) of the traffic through this particular crossing location have measured the average axle load and speed to be 14 tons and $135 \mathrm{~km} / \mathrm{h}$ respectively. As the traffic has been a mixture of different trains, both freight and passenger trains, the driven versus undriven axle ratio is therefore unknown. The crossing was not lubricated. The nominal chemical composition of the Hadfield manganese steel is given in Table 1.

Table 1: Chemical composition of Hadfield manganese steel.

\begin{tabular}{|c|c|c|c|c|c|c|}
\hline Element & $\mathrm{C}$ & $\mathrm{Mn}$ & $\mathrm{Cr}$ & $\mathrm{Si}$ & $\mathrm{P}$ & $\mathrm{Fe}$ \\
\hline wt.\% & $1-1.4$ & $12-13$ & $\sim 0.18$ & $0.4-0.6$ & $0.022-0.033$ & Balance \\
\hline
\end{tabular}

While some Hadfield manganese steel crossings are explosion hardened, this one was not.

The mechanical properties of the steel were obtained from tensile tests done at room temperature and $10^{-3} \mathrm{~s}^{-1}$ strain rate. The specimen for tensile testing was obtained at a depth of $20 \mathrm{~mm}$ from the wheel running surface (i.e at a position assumed to be free from any deformation due to wheel contact) along the longitudinal direction from a wing rail. The specimen was cylindrical dog bone shaped with a gauge length of $10 \mathrm{~mm}$ and gauge diameter of $5 \mathrm{~mm}$. The tensile test results are given in Table 2.

Table 2: Mechanical properties of undeformed Hadfield manganese steel.

\begin{tabular}{|l|l|l|l|l|}
\hline Tensile Strength & Yield Strength & Young's Modulus & Elongation & Hardness \\
\hline$\sim 750 \mathrm{MPa}$ & $\sim 365 \mathrm{MPa}$ & $\sim 203 \mathrm{GPa}$ & $20 \%$ & $\sim 220 \mathrm{HV}$ \\
\hline
\end{tabular}

For investigations of the crack network and the deformation layers, specimens were cut from the damaged nose, as shown in figure 1 . Vickers hardness measurements with a load of $1 \mathrm{~kg}$ and a dwell time of 20 seconds were used to study the microhardness distributions in the transverse section (i.e the TD/ND section) of the nose. A grid of measurements were made at intervals of $2 \mathrm{~mm}$ along the transverse direction and $0.3 \mathrm{~mm}$ from the rail running surface along the normal direction throughout the transverse section, and from these measurements a hardness map was constructed.

The microstructures were investigated using optical microscopy (OM) and scanning electron microscopy (SEM). Specimens for microstructural observations in OM were ground with Si-C paper ranging from grain 320 to 4000 followed by polishing by diamond paste to $1 \mu \mathrm{m}$ and etched with $4 \%$ Nital. 
For EBSD in the SEM, the specimen was ground and polished similarly down to $1 \mu \mathrm{m}$ and then polished with colloidal silica or OP-S for 40 minutes. The EBDS measurements were made using an acceleration voltage of $20 \mathrm{kV}$, aperture size of $60 \mu \mathrm{m}$ and working distance of $13.3 \mathrm{~mm}$. The specimen was scanned on the transverse surface in a square grid with a step size of $0.5 \mu \mathrm{m}$.
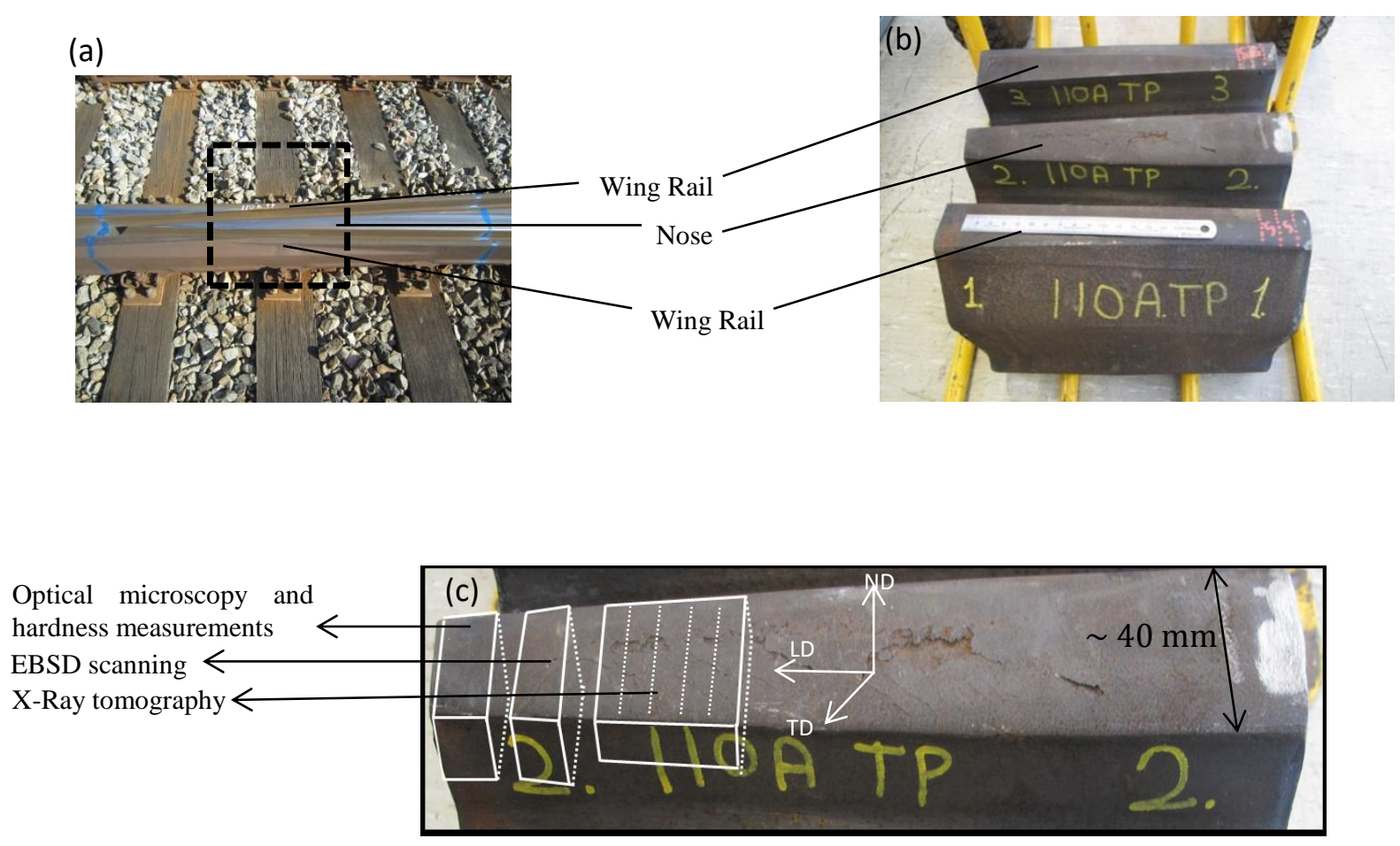

Figure 1: Sketches and photos showing where the specimens are taken. (a) A Hadfield manganese railway crossing with nose and wing rail on the track. (b) Part of Hadfield manganese steel crossing cut out from the track for the investigation. (c) Image with indications of the selected areas in the nose extracted for metallurgical characterization. ND, TD, LD represents normal direction, transverse direction and longitudinal direction respectively.

For X-ray computerized tomography, 5 specimens were cut from an area of the nose which had visual fatigue spallation (see figure 1c), each of them having a cross section of $\approx 10 \mathrm{~mm}$ by $40 \mathrm{~mm}$ by $10 \mathrm{~mm}$. Each of the specimens was scanned individually using a Zeiss Xradia Versa 520. A polychromatic X-ray beam was used with energies ranging up to $160 \mathrm{kV}$ from a tungsten target. A total of 1601 projections were acquired during a full specimen rotation. 3D maps were reconstructed by a Feldkamp algorithm for cone beam reconstruction [17] to $2 \mathrm{k} \times 2 \mathrm{k} \times 2 \mathrm{k}$ voxel volumes with a voxel size of $10 \mu \mathrm{m}$. The crack network was segmented and visualized using Avizo 3D software. The crack networks from different specimens were then stitched together to provide a 3D map of the crack morphology within a $50 \mathrm{~mm}$ by $40 \mathrm{~mm}$ by $10 \mathrm{~mm}$ volume of the nose.

\section{Results:}

\subsection{Hardness Measurements}


Figure 2 shows the hardness map of the nose. The wheel contact surface of the rail receives the maximum deformation where the deformation induced hardness is very high, nearly $600 \mathrm{HV}$, whereas the undeformed material hardness is only $220 \mathrm{HV}$. The black area at the top of the hardness map in figure 2 is caused by the lack of data due to the presence of cracks. Moving down from the running surface in to the material the hardness decreases as the extent of deformation decreases. The deformation gradient however extends quite deep into the rail, hardness values above $220 \mathrm{HV}$ are observed as deep as $10 \mathrm{~mm}$ from the running surface. This is visualized in figure 3, which shows the hardness profile along the normal direction at three positions in the hardness map. For all three positions, a similar exponential decrease in hardness is observed. Compared to pearlitic grade steel, the depth of hardening is significantly higher for a Hadfield manganese steel nose. In normal R260 or R220 grades pearlitic steel the hardness is reported to fall to base hardness within an average depth of 3-4 $\mathrm{mm}$ from the running surface [18-19].

\subsection{Optical Microscopy}

Figure 4 (a-d) shows the microstructure of the nose at different depths from the running surface. The microstructure of undeformed Hadfield manganese steel (figure 4d) is composed of very large equiaxed grains with an average grain size of $500 \mu \mathrm{m}$ and some inclusions in the microstructure. At the rolling contact surface, deformation bands can be seen in the grains (figure 4a). In normal pearlitic grade steel deformation causes the grains to become elongated in the direction of shear. However shearing of grains is not observed in the present Hadfield manganese steel, instead deformation bands form inside the grains. As the contact surface receives the maximum deformation, the density of these bands is highest at the surface. At increasing depth from the running surface (figure $4 b-4 c$ ) the density of the deformation bands decreases in agreement with the deformation hardening decreasing as seen in figure 3 . At the contact surface the deformation bands cross each other within the grains whereas at deeper locations the grains mostly have deformation bands in a single direction. The deformation bands are inhomogeneously distributed and have a wavy appearance, with the orientation and direction of the bands differing from grain to grain. These deformation bands can either be deformation induced mechanical twins or dislocation boundaries, which the optical microscopy is not capable of differentiating between. In some austenitic steels, martensitic transformation also imparts additional hardening, but in this investigation no martensite was found.

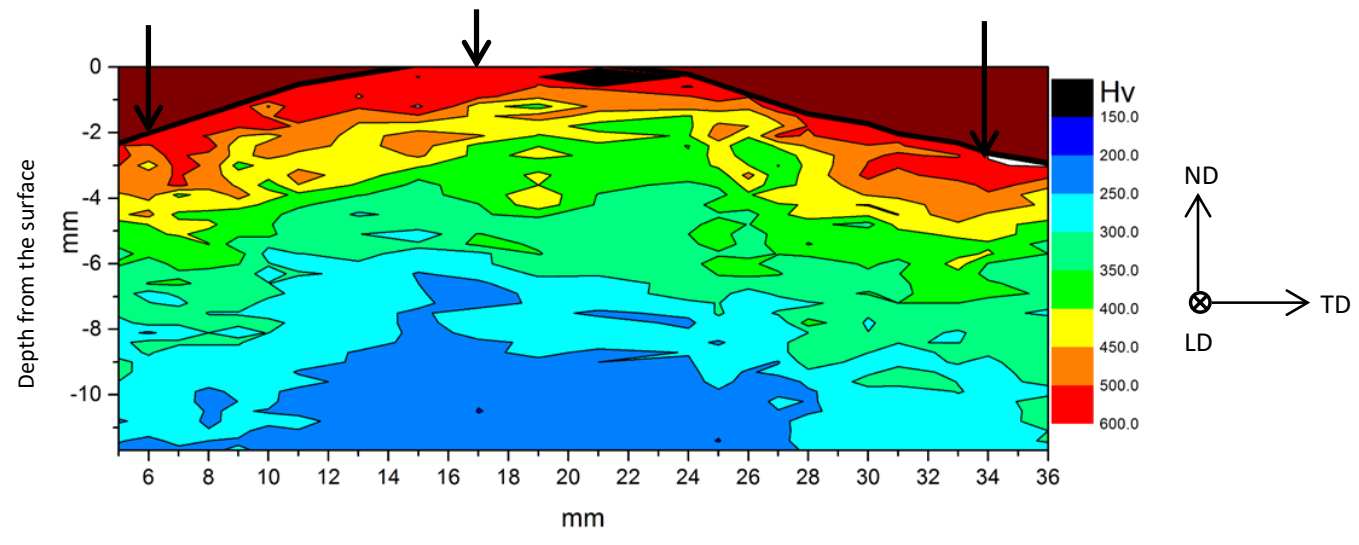

Figure 2: Hardness contour map of the transverse section of the nose of the Hadfield manganese crossing showing the gradient of deformation. The black area at the top running surface is due to lack of data points because of the presence of cracks. The black arrows at the top show where the hardness decrease profiles shown in figure 3 are taken. 


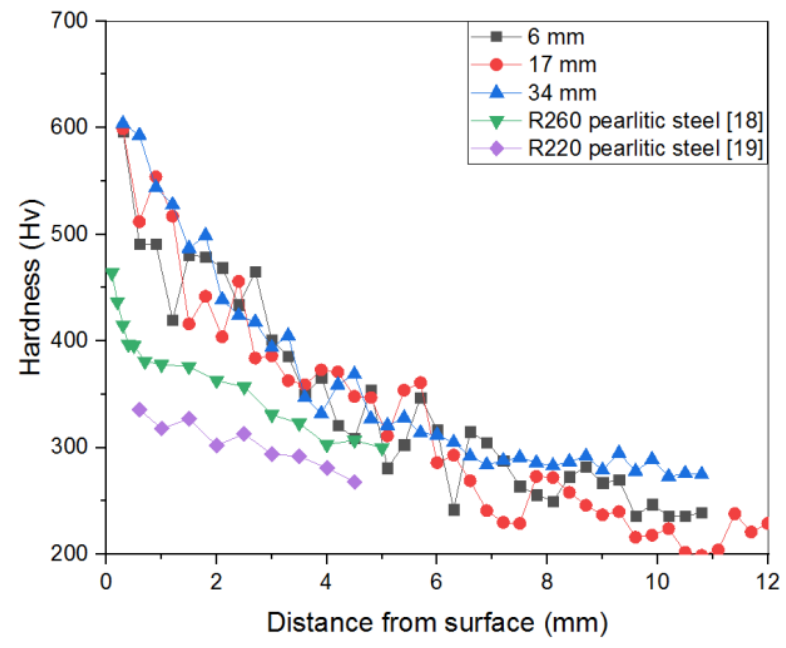

Figure 3: Decrease in hardness as a function of distance from the surface at the positions $6 \mathrm{~mm}, 17 \mathrm{~mm}$ and $34 \mathrm{~mm}$ along the transverse direction (see arrows in figure 2). (Data points for hardness decrease in pearlitic steel extracted from track has been obtained from literature [18-19]. The measurements are from the center of the running band.)

In figure 5, an optical micrograph of the crack network on the transverse surface is shown. Most of the cracks seem to originate from the wheel contact surface. The bigger cracks are at angles of nearly 35 degrees from the surface, extending around 2-3 $\mathrm{mm}$ into the rail and then change direction parallel to the running surface, which may lead to spallation. This is similar in nature to what is found in pearlitic grade steel subjected to rolling contact fatigue. There are some shallow angled small surface cracks as well, which also run parallel to the surface. The smaller cracks have angles ranging from 15 degrees to 30 degrees to the surface. Plastic deformation plays an important role in the propagation of the crack. Sometimes cracks can penetrate beneath, exceed the plastically deformed layer, however in this case the crack is confined within the first $2-3 \mathrm{~mm}$ from the running surface, well within the $10 \mathrm{~mm}$ thick plastically deformed layer. Indication of crack shielding can be observed, where two cracks initiate close to each other and only one of them grows and shields the propagation of the other due to stress relief. In figure 5, the propagation of crack 1 might have shielded the growth of crack 2 . Crack shielding can also be observed in case of branched cracks as we see for crack 3 , where the main crack propagation may have been interrupted by the growth of the branched crack. 

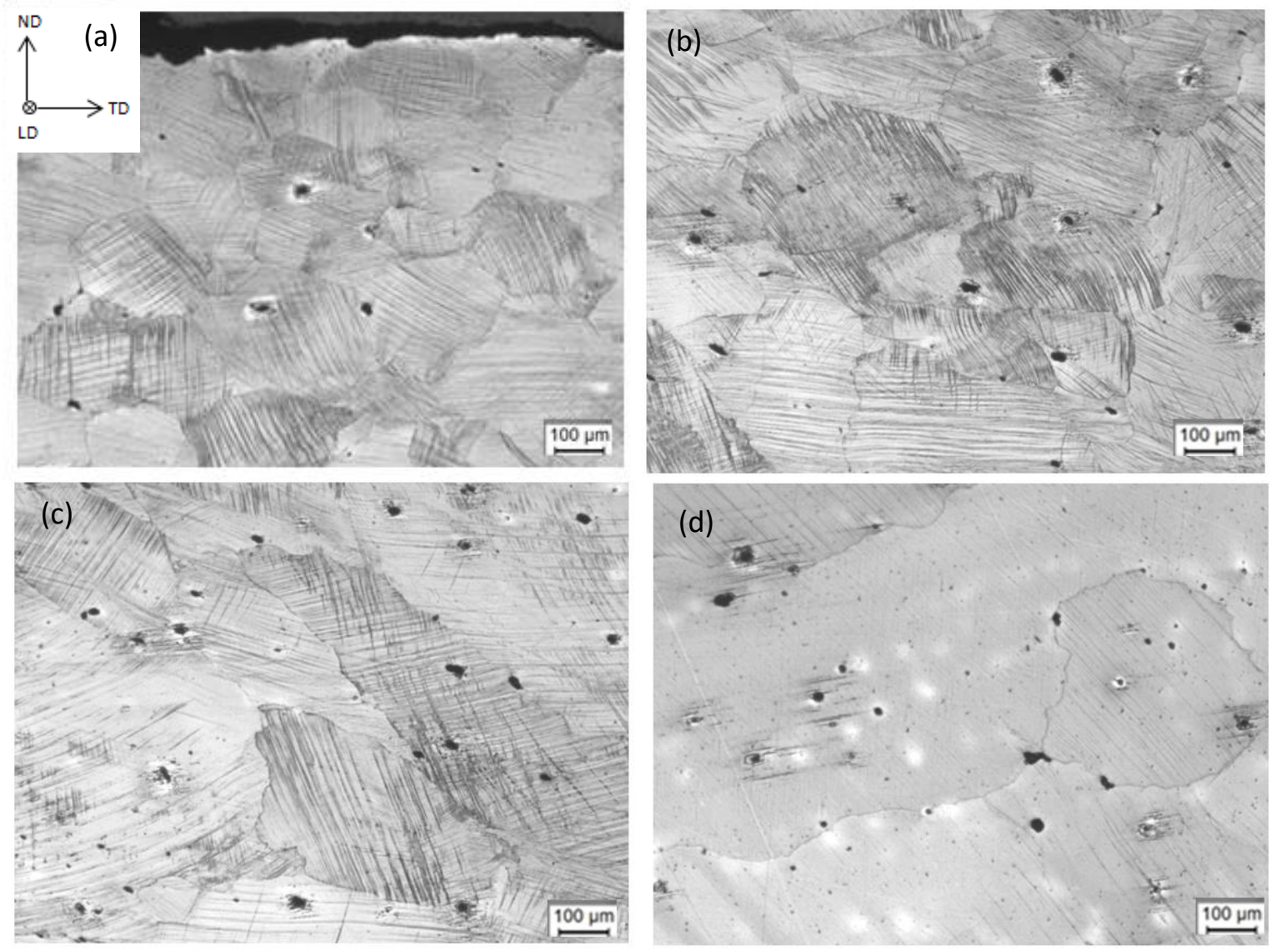

Figure 4: Optical microscope images of the transverse surface of the deformed Hadfield manganese steel crossing nose (a) at the rolling contact surface (b) $2 \mathrm{~mm}$ from the surface (c) $8 \mathrm{~mm}$ from the surface (d) $15 \mathrm{~mm}$ from the surface (largely without deformation).

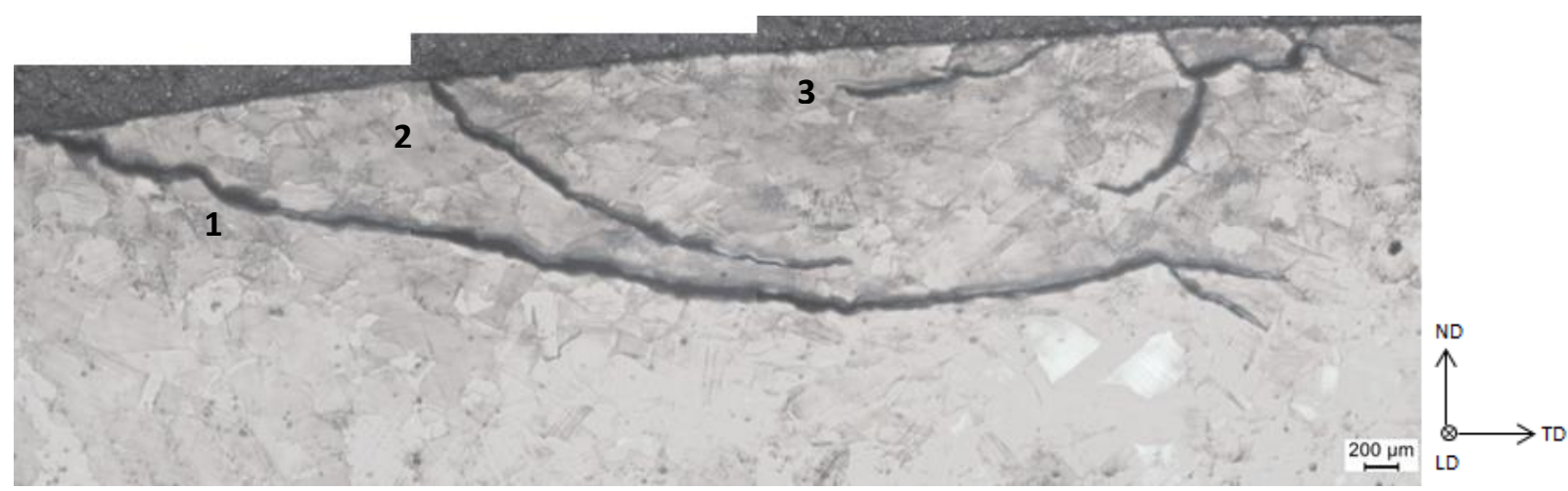

Figure 5: Optical microscope image of a crack network in the transverse surface showing a wavy crack propagation path along with crack branching.

\section{$3.3 X$-ray Computerized Tomography}

3D X-ray computerized tomography was used to get a 3D representation of the crack morphology. X-ray tomography reconstructions are 3D density maps, which allow detection of cracks due to the difference in density by applying an intensity threshold value. Each of the specimens were individually scanned and reconstructed, after which they were stitched together to give an overview of the crack network in a large volume. Figure 6(a) shows the 3D tomography image of the volume within the crack shown in figure 5 and a 2D section from the 3D data set is shown in figure 6(b). The surface morphology of the crack is much more evident in the $3 \mathrm{D}$ image although it is hard to show in a non-3D 
media. A comparison between the optical microscopy imaging of the crack (figure 5) and the 2D tomography section of the same cracks in figure 6(b) illustrates that with tomography it is possible to reconstruct the crack network with good spatial resolution and sufficient detail even though the voxel size in the reconstructions are $10 \mu \mathrm{m}$.
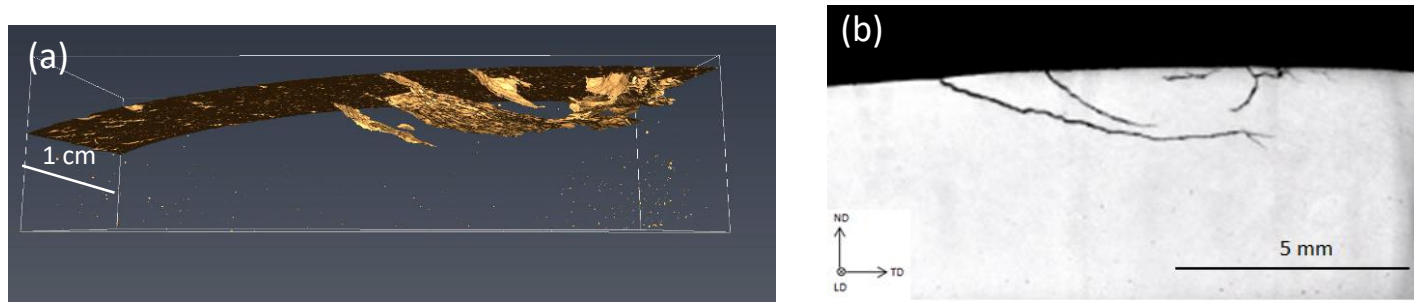

Figure 6: X-ray tomography of a volume containing the crack network shown in figure 5. (a) Crack network in 3D revealing the complete morphology of the crack network. (It is chosen to show the steel and air as transparent and the interface between them in yellow which makes the cracks as well as the rail surface visible.) (b) A 2D section taken from the data in figure (a) at a location close to shown in figure 5.
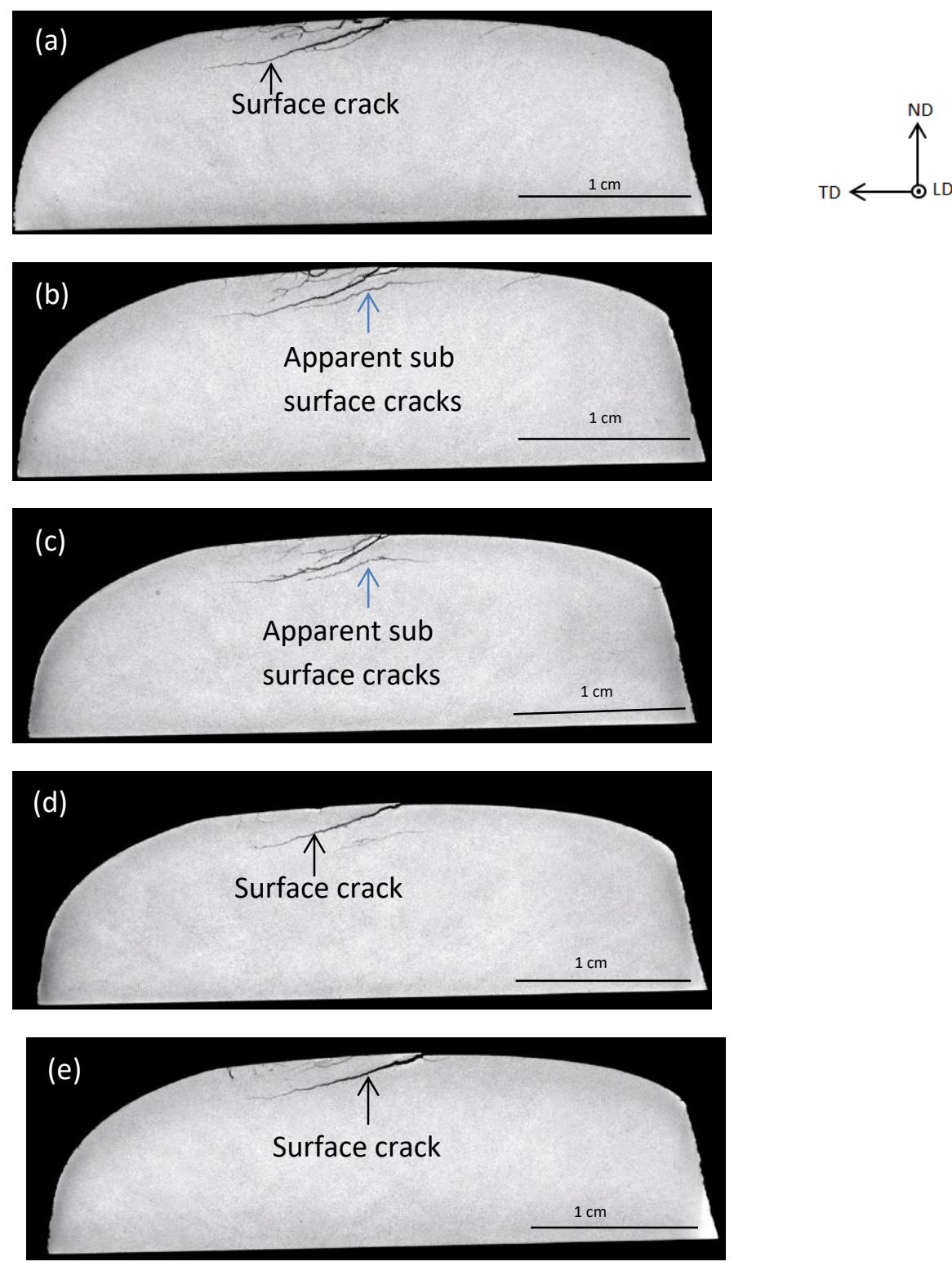
Figure 7: X-ray tomography of the crack network from one of the specimens visualized by 2D slices at different locations within $10 \mathrm{~mm}$ along the running direction. Example of surface crack has been poined in figures (a), (d) and

(e). The blue arrows in figures (b) and (c) point to cracks which appear as subsurface cracks in 2D images.

Five adjacent specimens were cut out from the area shown in figure 1, which contained some spallation. Figure 7(a-e) shows $2 \mathrm{D}$ slices from the tomographic reconstruction for one of the five specimens. The different images are from different positions along the longitudinal direction within a length of $10 \mathrm{~mm}$. From these images we can identify a big crack originating from the surface and running throughout the entire cross section of the specimen. The crack network is extensive and continuous through all the five scanned specimens, with different cracks and branches interacting with each other. These 2D images clearly show the need for a large overview in order to comprehend the crack network. For example, in figure 7(b-d) we see a sub-surface crack present, which is not evident in figure 7a or 7e. The crack shape changes continuously with location and may have connections to the surface at other locations, which are not evident from 2D slices.

Figure 8 shows the stitched 3-D tomography images of the crack network obtained from the five adjacent specimens. The samples are aligned next to each other separated by the width of the cutting blade. The steel and air are represented as being transparent and the colored area is the interface between them, making the crack network as well as the crossing nose surface visible. The figure shows the extent and severity of cracks beneath the surface of the crossing nose, also giving an overview of the spallation and the cracking related to it. At higher magnification the cracks are rough with ridges which are typical for rolling contact fatigue. Apart from the larger surface crack, the 3D scans shows that some smaller subsurface cracks are located at various depths. It is suggested that the maximum residual stresses in a crossing occur at certain depths from the contact surface and it is the combination of the contact and residual stresses that can lead to subsurface crack initiations [20]. Within the nose, many of the surface and subsurface cracks are interconnected, whereas some are propagating individually. Most of the cracks have a definite direction of propagation. The main crack network seen here continues throughout the $50 \mathrm{~mm}$ of the running direction, it is over $10 \mathrm{~mm}$ in length in the transverse direction and extends up to a depth of $3 \mathrm{~mm}$ from the running surface.

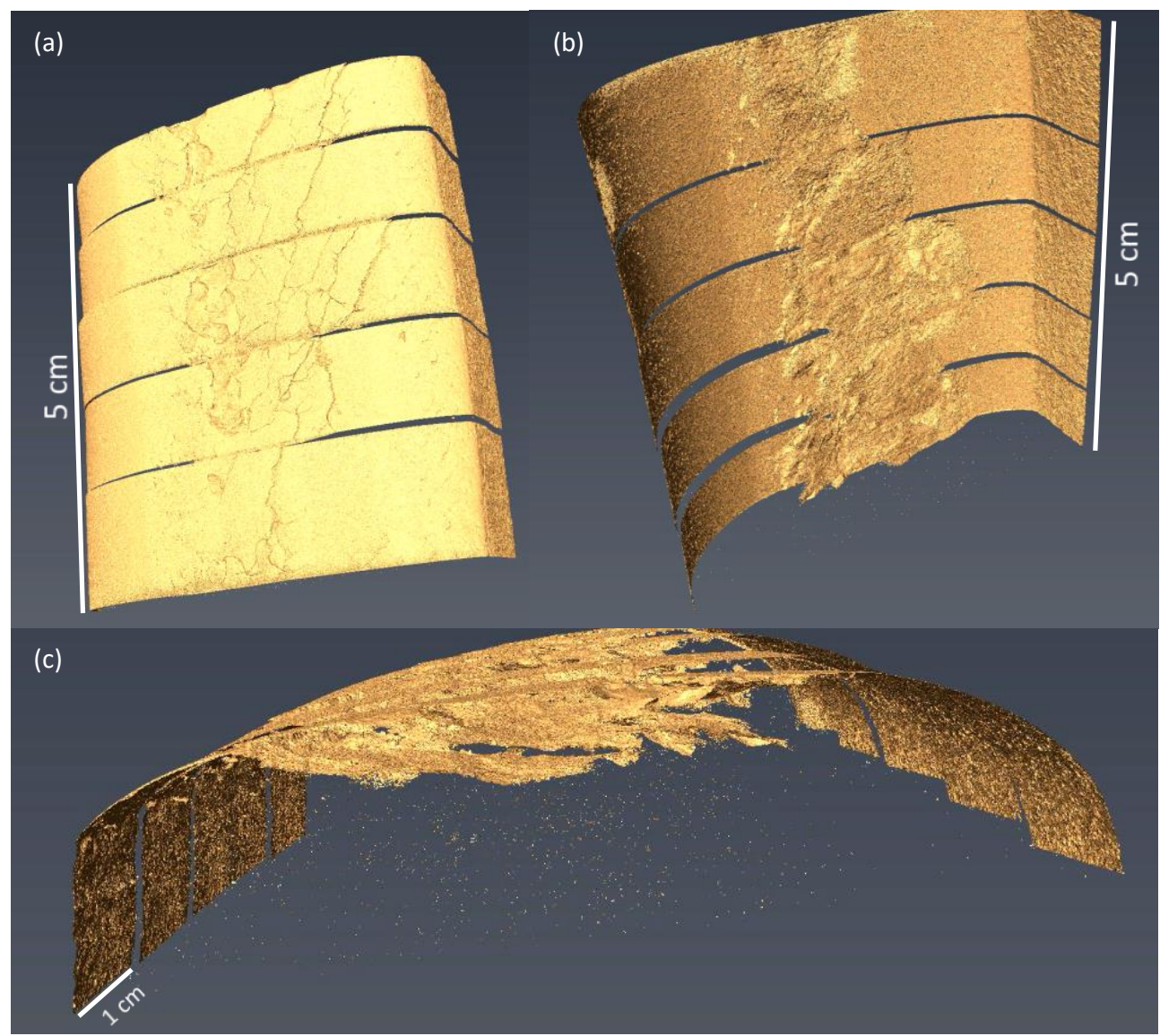

Figure 8: 3-D tomographic representation of the crack network in a volume of size $50 \mathrm{~mm}$ by $40 \mathrm{~mm}$ by $10 \mathrm{~mm}$. The surface of the rail including crack openings is made visible by performing a global segmentation thresholding. The steel 
and air are transparent and the interface between them is yellow which makes the cracks as well as the rail surface visible. (a) Top view of the nose showing the running surface with evident surface cracks and spallation. (b) The crack network as seen from within the crossing nose. (c) Transverse view of the crack network.

\subsection{EBSD}

Figure 9 shows maps of the microstructure near two of the cracks, close to the crack tips, obtained by EBSD. The maps show high density of mechanical twins (colored in white) and also deformation induced dislocation boundaries (colored in black). The density of these bands is not uniform through the grains and the direction of these bands also varies for different grains. Some orientations are more favorable for twin formation and have multiple twins whereas other grains are totally free from any deformation twins, consisting only of dislocation boundaries. All the deformation induced dislocation boundaries have only low $\left(<15^{\circ}\right)$ misorientation even at the severe deformation near the surface.

\section{(a)}

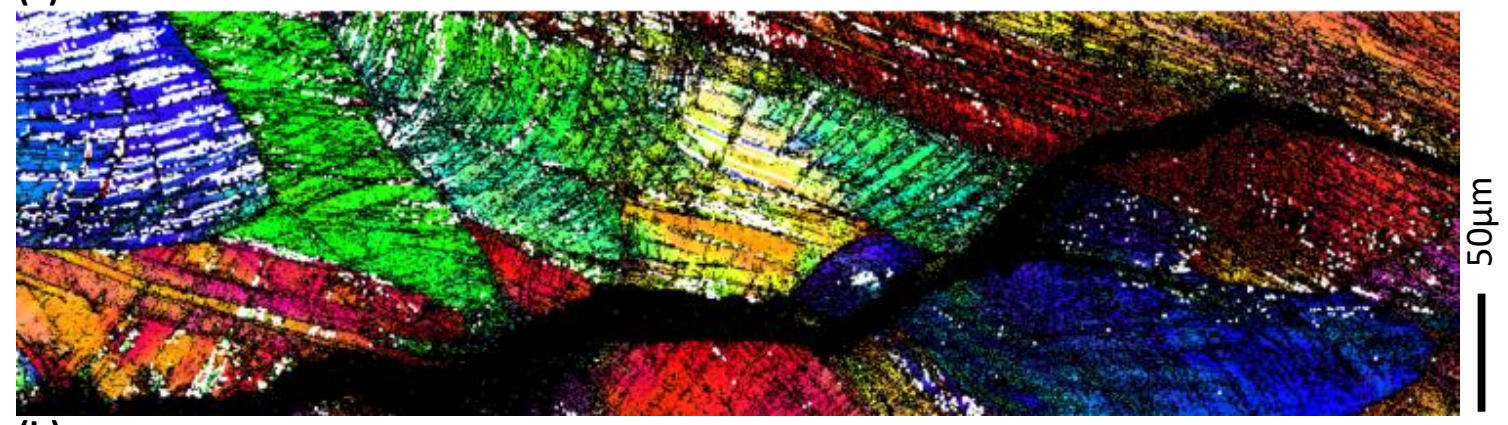

(b)
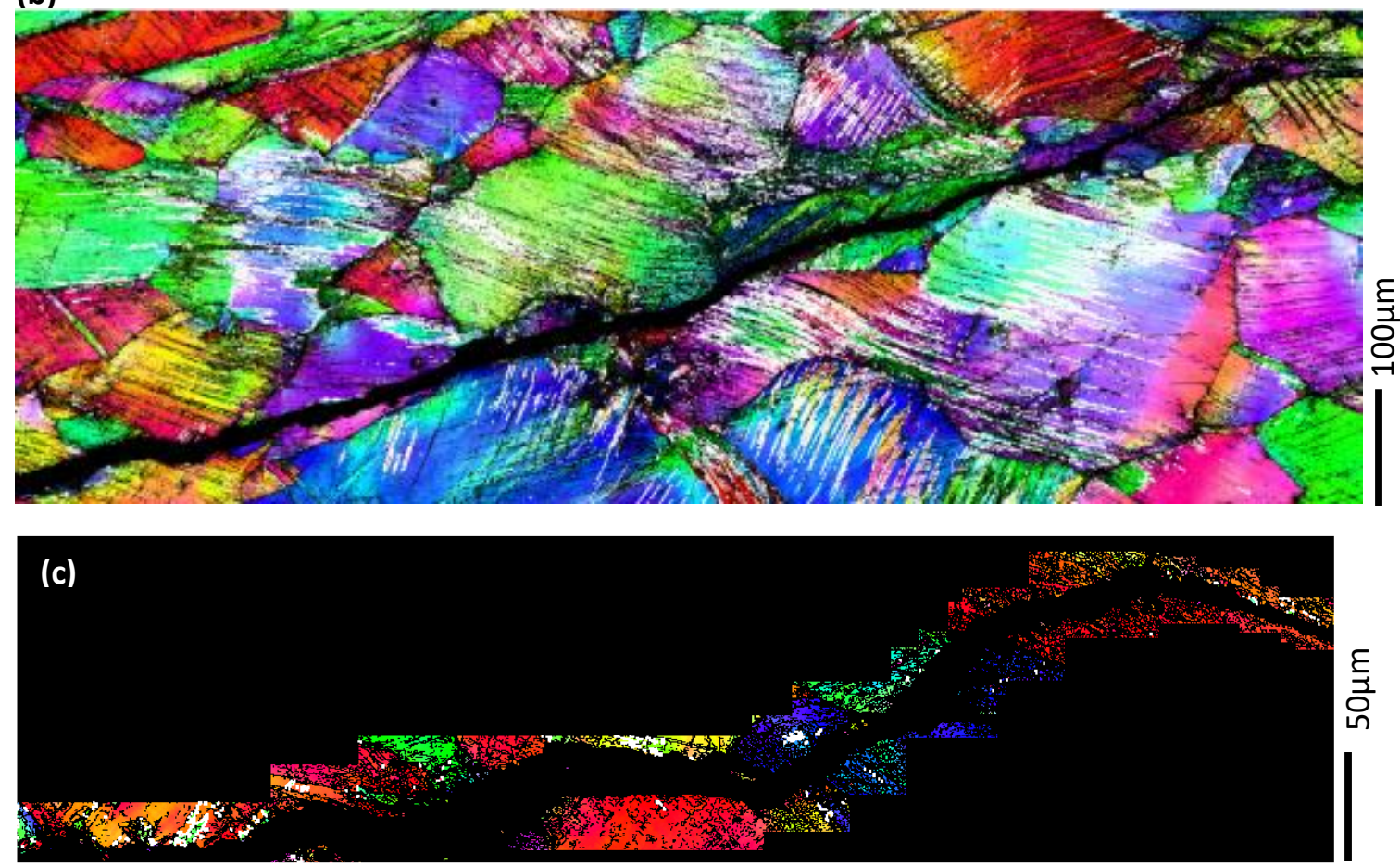

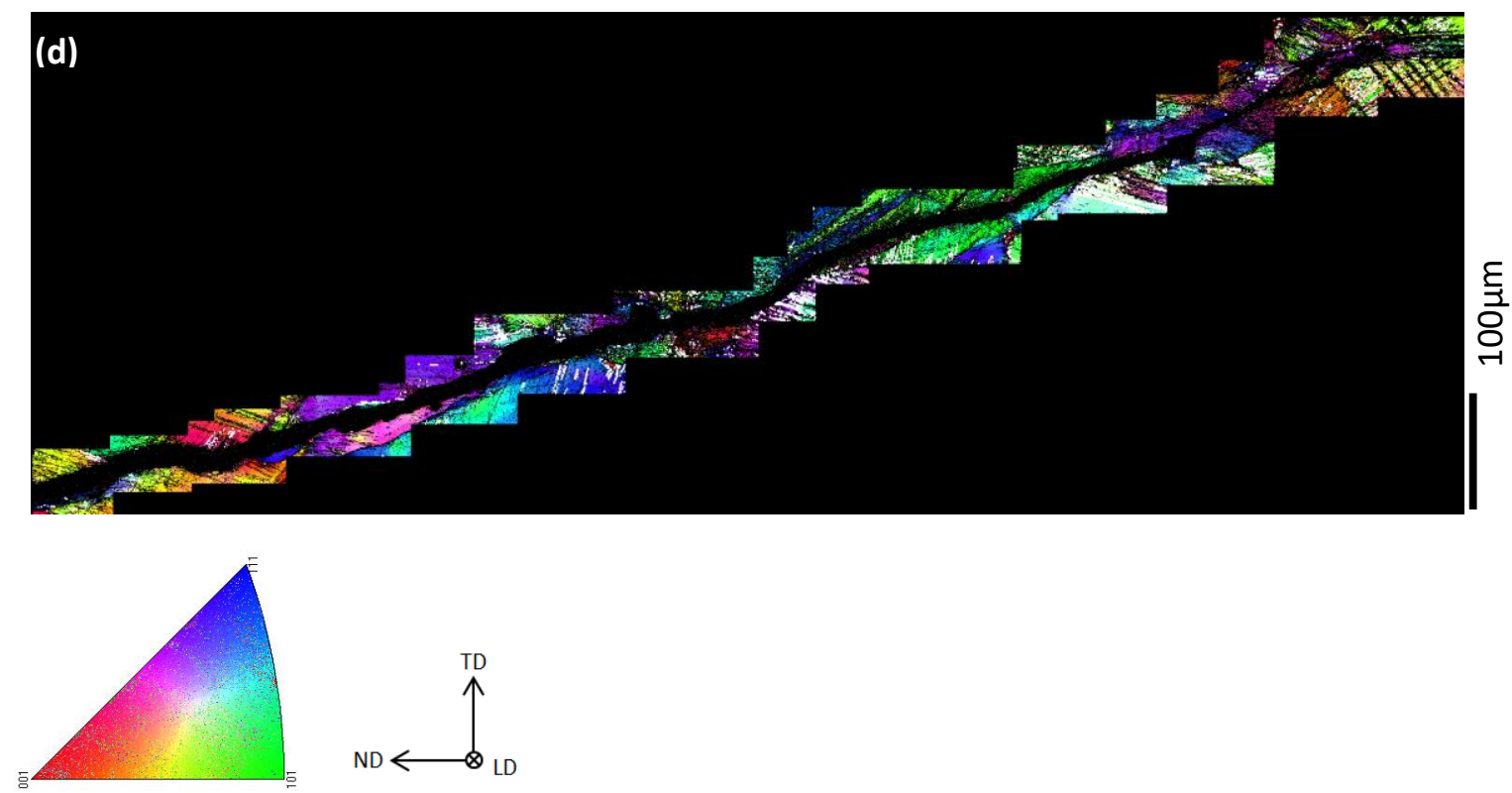

Figure 9: Maps obtained by EBSD showing the distribution of crystallographic orientations near two of the cracks within the nose. The colors correspond to the crystallographic orientation along the specimen surface normal direction, the white bands are deformation twins and the black bands are dislocation boundaries. (a) \& (b) the matrix around the two cracks, (c) \& (d) the area near the cracks selected for detailed analysis.

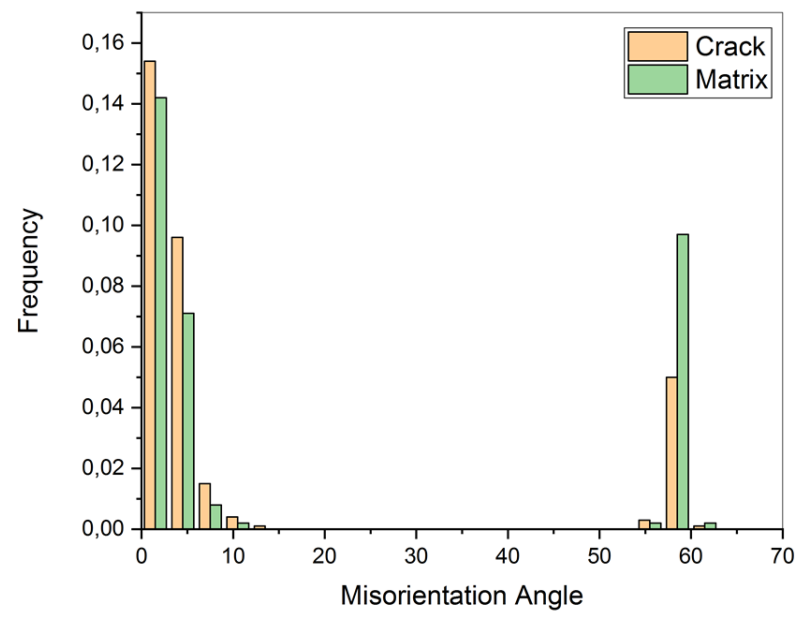

Figure 10: The frequency distribution of misorientation angles across boundaries within the area near cracks (see figure $9 \mathrm{c}$ and d) and the matrix away from the crack.

A comparison of misorientations in areas near the cracks and in the matrix away from them reveal that the matrix has a significantly higher twinning density compared to the areas near the cracks, see figure 10 . Thus the cracks tend to propagate through regions, which are free from twinning resulting into a wavy crack path. The crack network is mostly transgranular with only about $35 \%$ of the crack length along the grain boundaries (see Table 3 ) and it passes through grains of many different crystallographic orientations. There appears to be no preference for the crack to pass through any specific orientation, other than grains with twins are less likely to be cracked.

Table 3: Analysis of crack path, the percentage of crack length passing through grain interiors or along grain boundaries

\begin{tabular}{|l|l|l|} 
is given. Crack 1 is from figure 9c and crack 2 is from figure 9d. \\
\hline Crack & Grain interior & Grain boundary \\
\hline 1 & $65.33 \%$ & $34.66 \%$ \\
\hline
\end{tabular}




\begin{tabular}{|l|l|l|}
\hline 2 & $62.31 \%$ & $37.68 \%$ \\
\hline
\end{tabular}

\section{Discussion}

Rail-wheel contact causes both normal and shear strains in the rails due to rolling and sliding at the contact surface, which induces hardening at the surface. When the hardening reaches saturation, the surface becomes brittle and fatigue cracks start appearing leading to failure. The work hardening behavior is generally characterized by the strain hardening exponent (n); the greater the value of $n$, the greater is the work hardening. A hardening exponent of $n \sim 0.4$ was obtained from tensile testing of this Hadfield manganese steel whereas the exponent is $\sim 0.2$ for pearlitic grade steel also used for crossings. In pearlitic steels the microstructure becomes aligned in the shear strain direction at high plastic deformation. The two phase microstructure of ferrite and cementite in the pearlitic steel plays a role in the deformation mechanism and eventually crack initiation and propagation. The ferrite generally gets strained in the direction of the plastic deformation and cracks generally form along the proeutectoid ferrite grain boundaries as they are the soft part of the microstructure and strain harden the most [18-19,21-22]. Cracks tend to follow the weakest link in the microstructure, which causes waviness in the crack path. Beside the soft ferrite, inclusions, slags and other defects are weak links in the microstructure, which can initiate or lead to a change in direction of the crack or in many cases the formation of branches.

The deformation mechanism of Hadfield manganese steel is quite different from pearlitic grade rail steel. Although containing inclusions, the microstructure of the Hadfield manganese steels is more homogenous, being single phase austenite. In Hadfield manganese steel, deformation occurs by both dislocation and twinning mechanisms while for pearlitic grades it is only by dislocations. Apart from dislocation movements, generally the extra work hardening is associated with the low stacking fault energy of Hadfield manganese steels, which is favorable for twinning deformation [23-24]. Another reason contributing to the extra hardening in Hadfield manganese steel may be rearrangement of the carbon atoms from octahedral to tetrahedral sites [23]. Therefore, the deformation mechanism of Hadfield manganese steel can be attributed to interactions between different slip systems, dislocations and twins [25], interstitial carbon atoms and dislocations [26-27], and between twinning systems [28].

Optical and EBSD imaging in this work show the deformation of the austenite grains in Hadfield manganese steel is not uniform. Depending on the stress direction and orientation of the grains, some grains are more favorable for twinning whereas other grains only have deformation induced dislocation substructures. Even within the same grain different substructures can be present. This non-uniform deformation of the grains can lead to local stress concentrations and crack formation in Hadfield manganese steel. Once a crack forms it seems to be confined within the plastically deformed layer and follows the direction of plastic flow. The crack has a shallow angle to the surface, and after a certain distance of propagation within the material, it changes direction and runs parallel to the surface. Crack branching is also evident, as well as indications of crack shielding. The crack network is found to preferentially propagate through regions free from twinning as that is relatively softer compared to twinned regions.

The crack propagation morphology found in a Hadfield manganese steel crossing in this work is similar to what can be found in pearlitic grade steel used in normal tracks. Plastic deformation occurs leading to crack formation in both cases. The crack originates mostly at the surface where the loads are highest. After initiation, most of the cracks are confined within the plastically deformed layer, following the weakest links in the microstructures, ferrite grain boundaries in case of pearlite and softer non-twinned grains in Hadfield manganese steel. The profile of a crossing and the loading conditions are different from a straight track, therefore the mechanism leading to crack initiation and plastic deformation is different in the two types of material. However, once the crack has formed, its morphology and the network developed in both of them seem to be comparable. The observed crack network passes through several grains and most cracks have a shallow angle of origin propagating back to the surface, which is generally the same behavior seen in pearlite. It could be of interest for purposes of track maintenance on Hadfield manganese steel crossings that the damage progression is so similar to that of normal pearlititc steel straight track, irrespective of the very different steel grades and loading conditions for the two cases.

\section{Conclusion:}

The deformation and damage induced during service on the nose of a non-explosion hardened Hadfield manganese steel crossing has been investigated in this paper. The direction of traffic from the wing rail to the crossing nose had caused high impact stresses from the train wheels, leading to high deformation and severe crack formation of the crossing nose. The running surface has a very high deformation induced hardness of around $600 \mathrm{HV}$, with a hardness profile extending 
to a depth of $10 \mathrm{~mm}$. A high density of the deformation induced twins and dislocation boundaries in the austenitic grains was observed near the surface with decreasing density away from the surface related to the decrease in hardness.

The deformed microstructure of the Hadfield manganese steel contains a high density of deformation twins and dislocation boundaries but no shearing of grains are observed. EBSD imaging of the microstructure near the cracks indicate the crack propagation is predominately transgranular. The cracks mostly follow a path free from the twins through relatively soft grains causing the waviness in the crack path.

An extensive crack network was mapped in the damaged crossing nose using 3D X-ray tomography, capable of nondestructive scans accurately detecting the cracks in large sized specimens. Both surface and subsurface cracks were detected, some of them interconnecting. While Hadfield manganese steel has very different deformation mechanisms compared to normal pearilitic rail steels, the crack morphology is similar to cracks observed in the pearlitic grades. The crack network is confined in top layers of the plastically deformed rail with surface cracks originating at shallow angles to the surface and after reaching a certain depth of 2-3 mm running parallel to the contact surface.

\section{Acknowledgements:}

The authors gratefully acknowledge support from the Innovation Fund Denmark through the project "INTELLISWITCH - Intelligent Quality Assessment of Railway Switches and Crossings" (Grant no 4109-00003B).

\section{References:}

[1] B. Lv, M. Zhang, F. C. Zhang, C. L. Zheng, X. Y. Feng, L. H. Qian and X. B. Qin, Micro-mechanism of rolling contact fatigue in Hadfield steel crossing, International Journal of Fatigue 44 (2012) 273-278.

[2] S. L. Guo, D. Y. Sun, F. C. Zhang, X. Y. Feng and L. H. Qian, Damage of a Hadfield steel crossing due to wheel rolling impact passages, Wear 305 (2013) 267-273.

[3] M. Wiest, W. Daves, F. D. Fischer and H. Ossberger, Deformation and damage of a nose rail due to wheel passages, Wear 265 (2008) 1431-1438.

[4] J. H. Xiao, F. C. Zhang and L. H. Qian, Numerical simulation of stress and deformation in a railway crossing, Engineering Failure Analysis 18 (2011) 2296-2304.

[5] A. Johansson, B. Palsson, M. Ekh, J.C.O. Nielsen, M.K.A. Ander, J. Brouzoulis and E. Kassa, Simulation of wheel-rail contact and damage in switches \& crossings, Wear 271 (2011) 472-481.

[6] A. Tejada, A. Lau, I. Santos and R. Fongemie, Numerical simulation of track settlement using a multibody dynamic software a holistic approach, in A.T. Fleury, D.A. Rade and P.R.G. Kurka (Ed), Proceedings of the XVII International Symposium on Dynamic Problems of Mechanics, Sao Paolo, Brazil, March 5-10, 2017, ABCM - Brazilian Society of Mechanical Sciences.

[7] L. Qian, X. Feng and F. Zhang, Deformed microstructure and hardness of Hadfield high manganese steel, Materials Transactions 52(8) (2011) 1623-1628.

[8] F.C. Zhang, B. Lv, T. S. Wang, C. L. Zheng, M. Li and M. Zhang, Microstructure in worn surface of Hadfield steel crossing, International Journal of Modern Physics B 23(6 \& 7) (2009) 1185-1190.

[9] M. Schilke, N. Larijani and C. Persson, Interaction between cracks and microstructure in three dimensions for rolling contact fatigue, Fatigue and Fracture of Engineering Materials and Structures 37 (2014) 280-289.

[10] C. Jessop, J. Ahlström, L. Hammar, S. Fæster and H. K. Danielsen, 3D characterization of rolling contact fatigue crack networks, Wear 366-367 (2016) 392-400.

[11] Y. Zhou, X. Zheng, J. Jiang and D. Kuang, Modeling of rail head checks by X-ray computed tomography scan technology, International Journal of Fatigue 100 (2017) 21-31.

[12] J. E. Garnham, D. I. Fletcher, C. L. Davis and F. J. Franklin, Visualization and modelling to understand rail rolling contact fatigue cracks in three dimensions, Proceedings of the Institution of Mechanical Engineers, Part F: Journal of Rail and Rapid Transit 225 (2016) 165-178.

[13] W. Zhong, J. J. Hu, Z. B. Li, Q. Y. Liu and Z. R. Zhou, A study of rolling contact fatigue crack growth in U75V and U71Mn rails, Wear 271 (2011) 388-392.

[14] J. Brouzoulis and M. Ekh, Crack propagation in rails under rolling contact fatigue loading conditions based on material forces, International Journal of Fatigue 45 (2012) 98-105. 
[15] M. Naeimi, Z. Li, Z. Qian, Y. Zhou, J. Wu, R. H. Petrov, J. Sietsma and R. Dollevoet, Reconstruction of the rolling contact fatigue cracks in rails using X-ray computed tomography, NDT and E International 92 (2017) 199-212.

[16] X. Y. Feng, F.C. Zhang, C.L. Zheng and L. Bo, Micromechanics behavior of fatigue cracks in Hadfield steel railway crossing, Science China Technological Sciences 56 (5) (2013) 1151-1154.

[17] L.A. Feldkamp, L.C. Davis and J.W. Kress, Practical cone-beam algorithm, Journal of the Optical Society of America A 1(6) (1984) 612-619.

[18] J. E. Garnham and C. L. Davis, Very early stage rolling contact fatigue crack growth in pearlitic rail steels, Wear 271 (2011) 100-112.

[19] H. C. Eden, J. E. Garnham and C. L. Davis, Influential microstructural changes on rolling contact fatigue crack initiation in pearlitic rail steels, Materials Science and Technology 21(6) (2007) 623-629.

[20] J. H. Xiao, F. C. Zhang and L. H. Qian, Contact stress and residual stress in the nose rail of a high manganese steel crossing due to wheel contact loading, Fatigue and Fracture of Engineering Materials and Structures 37 (2014) 219-226.

[21] J. E. Garnham and C. L. Davis, The role of deformed rail microstructure on rolling contact fatigue initiation, Wear 265 (2008) 1363-1372.

[22] J. E. Garnham, F. J. Franklin, D. I. Fletcher, A. Kapoor and C. L. Davis, Predicting the life of steel rails, Proceedings of the Institution of Mechanical Engineers, Part F: Journal of Rail and Rapid Transit 221(1) 2007 23-33.

[23] P. H. Adler, G. B. Olson and W. S. Owen, Strain hardening of Hadfield manganese Steel, Metallurgical Transaction A 17A (1986) 1725-1737.

[24] I. Karaman, H. Sehitoglu, K. Gall, Y. I. Chumlyakov and H. J. Maier, Deformation of single crystal Hadfield steel by twinning and slip, Acta Materialia 48 (2000) 1345-1359.

[25] E. G. Astafurova, M. S. Tukeeva, G. G. Zakharova, E. V. Melnikov and H. J. Maier, The role of twinning on microstructure and mechanical response of severely deformed single crystals of high-manganese austenitic steel, Materials Characterization 62 (2011) 588-592.

[26] Y. N Dastur and W.C. Leslie, Mechanism of work hardening in Hadfield manganese steel, Metallurgical Transaction A 12A (1981) 749-759.

[27] W. S. Owen and M. Grujicic, Strain ageing of austenitic Hadfield manganese steel, Acta Materialia 47(1) (1999) 111-126.

[28] C. Efstathiou and H. Sehitoglu, Strain hardening and heterogeneous deformation during twinning in Hadfield steel, Acta Materialia 58 (2010) 1479-1488. 